\title{
Simulation Performance of PID and Fuzzy Logic Controller for Higher Order System
}

\author{
Pankaj Mohindru \\ Assistant Professor \\ Punjabi university, Patiala, \\ India
}

\author{
Gaurav Sharma \\ Student of Punjabi university \\ Patiala, India
}

\author{
Pooja \\ Assistant Professor \\ Punjabi universityPatiala, India
}

\begin{abstract}
The proportional-integral derivative controller (PID Controller) is a control loop feedback mechanism (Controller) widely used in industry. The high demand of PID controller is due to its fine control capabilities in a wide range of operating conditions. This paper presents design of PID controller using Ziegler-Nichols (ZN) technique for higher order systems. A fuzzy logic controller using simple approach and smaller rule set is also proposed. The aim of designed fuzzy controller is to present better control than PID controller. The simulation is done using Matlab/Simulink by comparing the performance of two controllers for higher order system. It is finally observed that fuzzy controller gives much better result than PID controller.
\end{abstract}

\section{Keywords}

PID controller, Higher order plant, Z-N tuning, Fuzzy logic controller, Simulation

\section{INTRODUCTION}

It is eminent that more than $95 \%$ of the control loops are PID controller type in process control [5]. The PID controllers are used in wide range of problems like DC motor, Automotive, Air flight control, etc. PID controller provides powerful and reliable performance in most control systems. A PID controller calculates an error value on the basis of difference between measured process variable and desired set point. The controller attempts to minimize the error by adjusting the tuning parameter [4]. The PID controller involves three separate constant parameter proportional $(\mathrm{P})$, integral (I), derivative (D). These values can be interpreted in term of time proportional $(\mathrm{P})$ which depends on the present error, integral (I) which depends on growth of past value and derivative (D) which predicts the future error. The quality of control in a system depends upon settling time (ts), rise time (tr) and overshoot (Mp) [9].These timing parameters are optimally reduced to avoid undesirable overshoots $(\mathrm{Mp})$ longer settling time (ts) and many other variations. A PID controller has been designed for higher order system using Ziegler-Nichlos frequency response method and its performance has been observed. The Ziegler-Nichlos tuned controller parameters are fine tuned to get satisfactory closed loop performance. The field of fuzzy logic control has been making fast progress in recent years. Fuzzy logic control has been widely implemented for nonlinear, higher order and time delay system [2]. A fuzzy logic controller has been proposed with simple approach and smaller set of rules [1]. This paper has been organized as following; Section I depicts the introduction of the paper. Section II explains the generalized tuning parameters of PID controller. Section III describes the design consideration for higher order system. Section IV reveals the design of PID controller using Z-N tuning and fine tuning techniques. Section $\mathrm{V}$ describes the design of fuzzy logic controller and a summary table of various results obtained through various techniques. Section VI gives general conclusions.

\section{GENERALISED TUNING PARAMETERS OF PID CONTROLLER}

The PID controllers have a wide range of applications in industrial control because of its simple control structure .The PID controllers require less plant information than a complete mathematical model. In this way, the controller parameters can be adjusted with a minimum effort. One survey of Desborough and Miller (2002) indicates that more than 97\% of regulatory controllers utilize the PID algorithms [5].

There are many versions of a PID controller [21].In this study, we consider a controller described by Equation (1)

$u(t)=\left[e(t)+\frac{1}{T_{i}} \int_{0}^{t} e(\tau) d \tau+T_{d} \frac{d e(t)}{d t}\right]$

where, $u(t)$ is the input signal sent to the plant model, e $(t)=$ $r(t)-y(t)$. e $(t)$ is the error, $r(t)$ is the reference input signal and $y(t)$ is the output signal respectively. The parameters $K_{p}, T_{i}$ and $\mathrm{T}_{\mathrm{d}}$ are the tuning parameters.

A PID controller is described by the following transfer function in the continuous s-domain [16]

$$
\mathrm{G}_{\mathrm{c}}(\mathrm{s})=\mathrm{K}_{\mathrm{p}}+\frac{\mathrm{K}_{\mathrm{i}}}{\mathrm{s}}+\mathrm{K}_{\mathrm{d}} \mathrm{s}
$$

Another way to write above equation (2) is articulated through equation (3)

$$
\mathrm{G}_{\mathrm{c}}(\mathrm{s})=\mathrm{K}_{\mathrm{P}}\left[1+\frac{1}{\mathrm{~T}_{\mathrm{I}} \mathrm{s}}+\mathrm{T}_{\mathrm{d}} \mathrm{s}\right]
$$

Where $K_{p}$ is the proportional gain, $K_{i}$ is the integration coefficient and $K_{d}$ is the derivative coefficient. $\mathbf{T}_{\mathbf{i}}$ is known as integral action time and $\mathbf{T}_{\mathbf{d}}$ is known as derivative action time. These types of controllers have three different adjustments $\left(\mathrm{K}_{\mathrm{p}}, \mathrm{T}_{\mathrm{i}}\right.$, and $\left.\mathrm{T}_{\mathrm{d}}\right)$, which interacts with each other. It is always very difficult and time consuming to tune these three parameters in order to get best performance according to the design specification of the system.

\section{DESIGN CONSIDERATION FOR HIGHER ORDER SYSTEM}

A PID controller is being designed for a higher order system for transfer function as given below 


$$
G(s)=\frac{32}{s^{3}+8 s^{2}+9 s}
$$

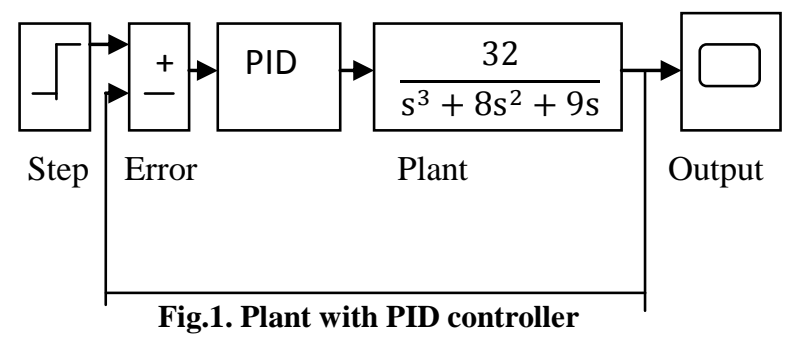

The simulink model of the PID controller and the plant with unity feedback is shown in Fig.1. The authors have proposed design of (i) PID controller using Z-N technique (ii) fuzzy logic controller through which the closed loop system exhibits small overshoot $\left(\mathrm{M}_{\mathrm{p}}\right)$ and settling time $\left(\mathrm{t}_{\mathrm{s}}\right)$ with zero steady state error $\left(\mathrm{e}_{\mathrm{ss}}\right)$.

\section{DESIGN OF PID CONTROLLER}

Tuning of conventional controller has been done by the Ziegler-Nichols method which is mostly used in industrial PID tuning. Routh's stability criterion method is used to determine the initial value of $\mathrm{Kp}, \mathrm{Ki}$ and $\mathrm{Kd}$.

Table.1: Ziegler-Nichols tuning method

\begin{tabular}{|l|l|l|l|}
\hline CONTROLLER & $\mathbf{K}_{\mathbf{p}}$ & $\mathbf{K}_{\mathbf{i}}$ & $\mathbf{K}_{\mathbf{d}}$ \\
\hline PID & $0.60 \mathrm{~K}_{\mathrm{u}}$ & $2 * \mathrm{~K}_{\mathrm{u}} / \mathrm{T}_{\mathrm{u}}$ & $\mathrm{K}_{\mathrm{u}} * \mathrm{~T}_{\mathrm{u}} / 8$ \\
\hline
\end{tabular}

The frequency response method as suggested by ZieglerNichols is applied for design of PID controller [13].

By setting $T_{i}=\infty$ and $T_{d}=0$ and using proportional control action $\left(\mathrm{K}_{\mathrm{p}}\right)$ only, the value of gain is increased from 0 to a critical value $K_{u}$ at which the output first exhibits oscillations. $\mathrm{T}_{\mathrm{u}}$ is known as period of oscillation. The unit step response for different values of gain $\mathrm{K}_{\mathrm{p}}$ were observed. The step response for $\mathrm{K}_{\mathrm{p}}=2.25$ is shown in Fig.2.

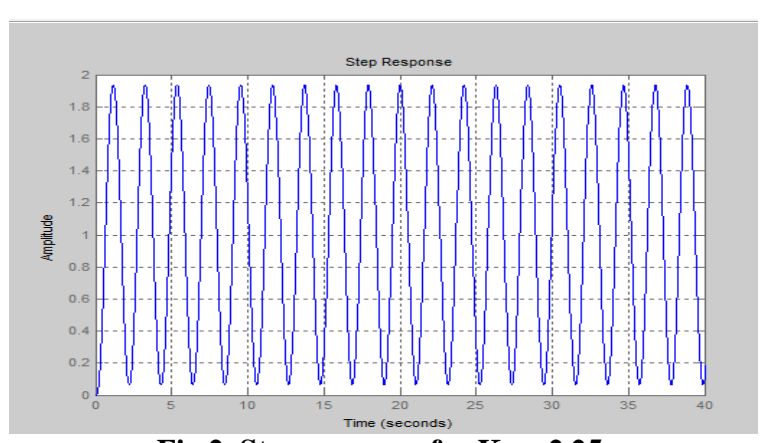

Fig.2. Step response for $K_{p}=\mathbf{2 . 2 5}$

The above response clearly shows the sustained oscillation occurs at $K_{p}=K_{u}=2.25$. The period of oscillation $T_{u}$ obtained from the time response is 2.11 .
The value of Ziegler-Nichlos tuning parameters are $\mathrm{K}_{\mathrm{p}}=$ $0.6 * \mathrm{~K}_{\mathrm{u}} \quad=1.35, \quad \mathrm{~T}_{\mathrm{i}}=0.5 * \mathrm{~T}_{\mathrm{u}}=1.055, \quad \mathrm{~K}_{\mathrm{i}}=\mathrm{K}_{\mathrm{p}} / \mathrm{T}_{\mathrm{i}}=1.28$, $\mathrm{T}_{\mathrm{d}}=0.125 * \mathrm{~T}_{\mathrm{u}}=0.264, \mathrm{~K}_{\mathrm{d}}=\mathrm{K}_{\mathrm{p}} / \mathrm{T}_{\mathrm{d}}=0.36$. The unit step response of closed loop system with $\mathrm{K}_{\mathrm{p}}=1.35, \mathrm{~K}_{\mathrm{i}}=1.28, \mathrm{~K}_{\mathrm{d}}=0.36$ shows that in Fig.3. It is also noted that overshoot $M_{p}=60.7 \%$, Rise time $t_{r}=0.43 \mathrm{sec}$ and Settling time $t_{s}=7.43 \mathrm{sec}$. Both $M_{p}$ and $t_{s}$ are too large.

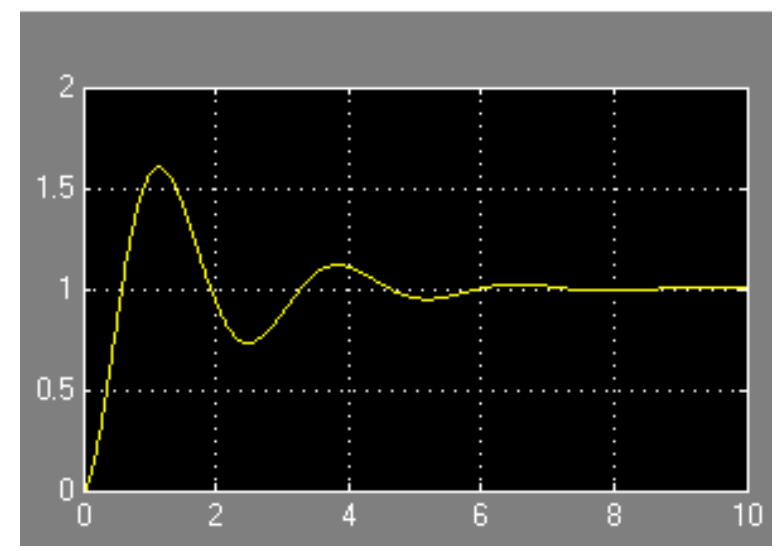

Fig.3. Step response for $K_{p}=1.35, K_{i}=1.28, K_{d}=0.36$

The unit step response of closed loop system with Fine-Tuned PID controller parameters are $\mathrm{K}_{\mathrm{p}}=4.2, \mathrm{~K}_{\mathrm{i}}=2.59, \mathrm{~K}_{\mathrm{d}}=2.2$ is shown below in Fig.4. Here it is observed that overshoot is $M_{p}=35.5 \%$, rise time $t_{r}=0.165 \mathrm{sec}$ and settling time $t_{s}=2.03$ sec. Both $\mathrm{Mp}$ and ts are smaller as compared to the initial values obtained from Ziegler Nichols method.

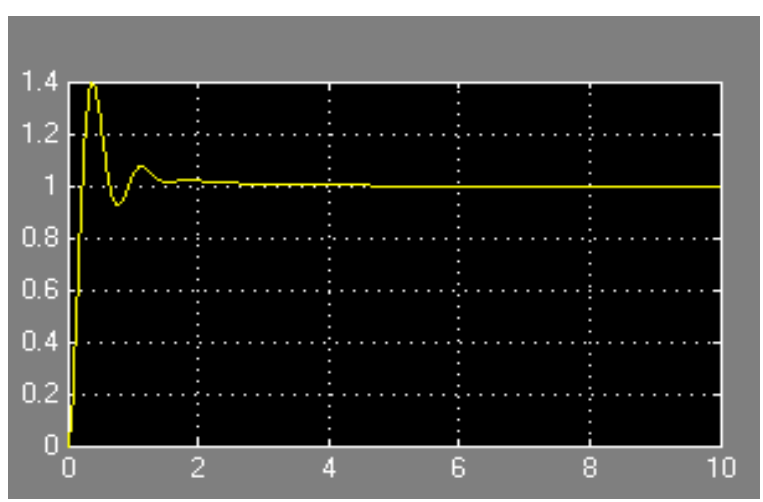

Fig.4. Step response for $K p=4.2, K i=2.59, K_{d}=2.2$

\section{DESIGN OF FUZZY LOGIC CONTROLLER (FLC)}

The simulink model of the fuzzy logic controller and the plant with unity feedback is shown in Fig.5. 


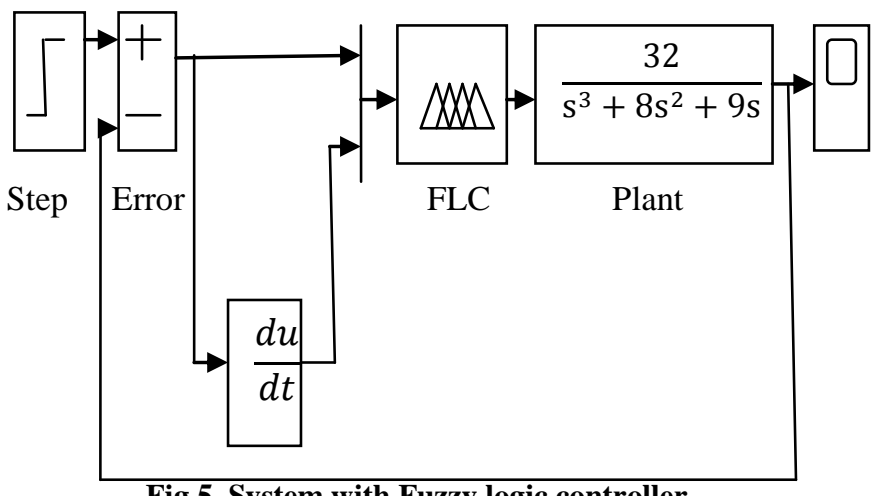

Fig.5. System with Fuzzy logic controller

The fuzzy logic controller has two inputs which are error(e) and the rate of change in error(de). Error is the difference between the reference value and the output of the controller. The rate of change in error (de) is the difference between the error at time $t$ and $(\mathrm{t}-1)$ [21].

These inputs have seven membership functions with linguistic variable name as Negative Big (NB), Negative Medium (NM), Negative Small (NS), Zero Error (ZE), Positive Small (PS), Positive Medium (PM), Positive Big (PB). The fuzzy logic controller output has the same membership functions as fuzzy logic controller inputs. Fig.6 and Fig.7 shows the inputs membership functions and Fig.8 shows output membership functions.

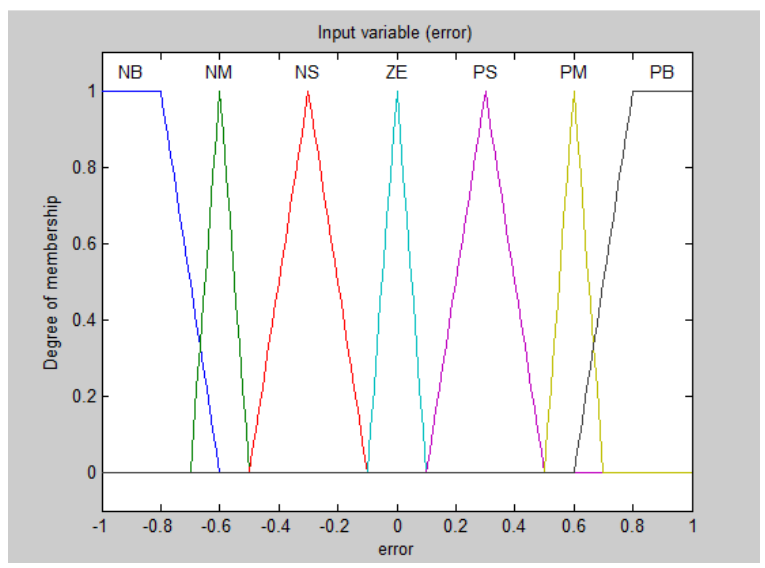

Fig.6. Membership function of input Error

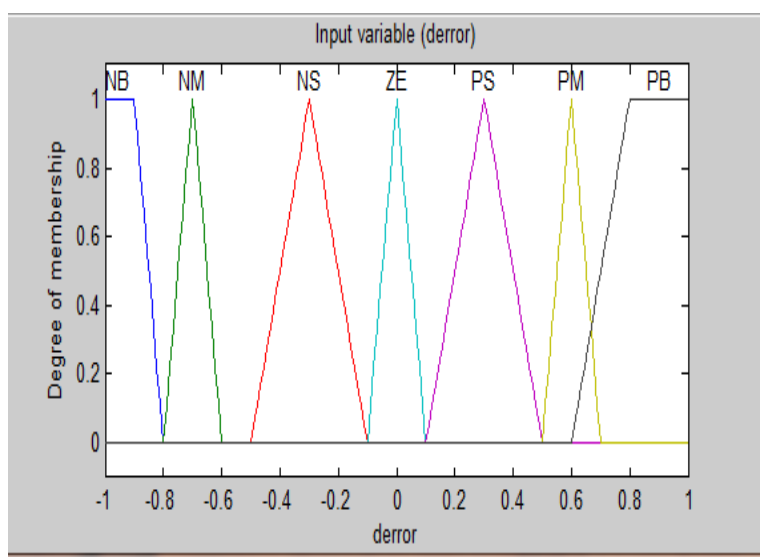

Fig.7. Membership function of input change in Error (de)

It has been observed while designing linguistic rules that 49 rules are sufficient to get the best possible results. There is no positive effect on output response of the system beyond 49 rules as they cover all possible situations as shown in Table. 2 given below.

Table.2. Fuzzy rules

\begin{tabular}{|l|l|l|l|l|l|l|l|}
\hline e/de & NB & NM & NS & ZE & PS & PM & PB \\
\hline NB & NB & NB & NB & NM & NS & NS & ZE \\
\hline NM & NB & NM & NM & NM & NS & ZE & PS \\
\hline NS & NB & NM & NS & NS & ZE & PS & PM \\
\hline ZE & NB & NM & NS & ZE & PS & PM & PB \\
\hline PS & NM & NS & ZE & PS & PS & PM & PB \\
\hline PM & NS & ZE & PS & PM & PM & PM & PB \\
\hline PB & ZE & PS & PS & PM & PB & PB & PB \\
\hline
\end{tabular}

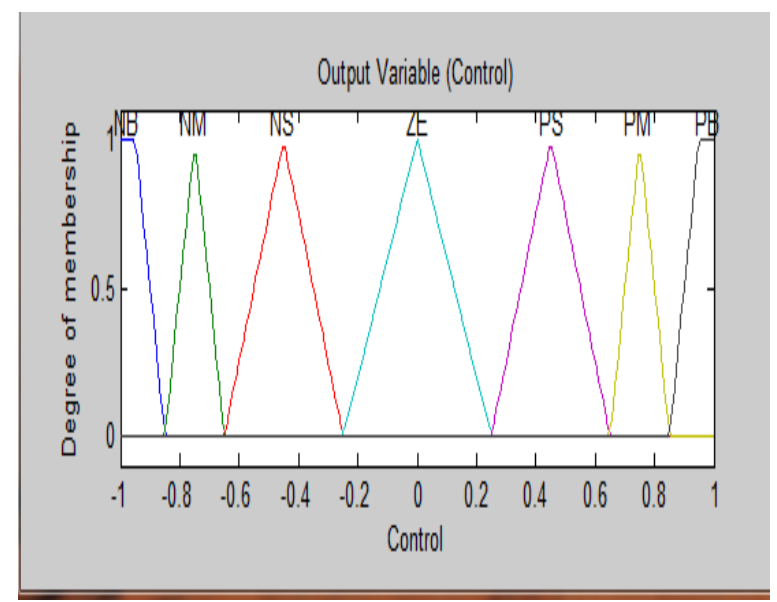

Fig.8. Membership function of output

The fuzzy inference is designed using fuzzy toolbox available in MATLAB Fig.9. Shows the layout of the fuzzy inference in the fuzzy logic controller.

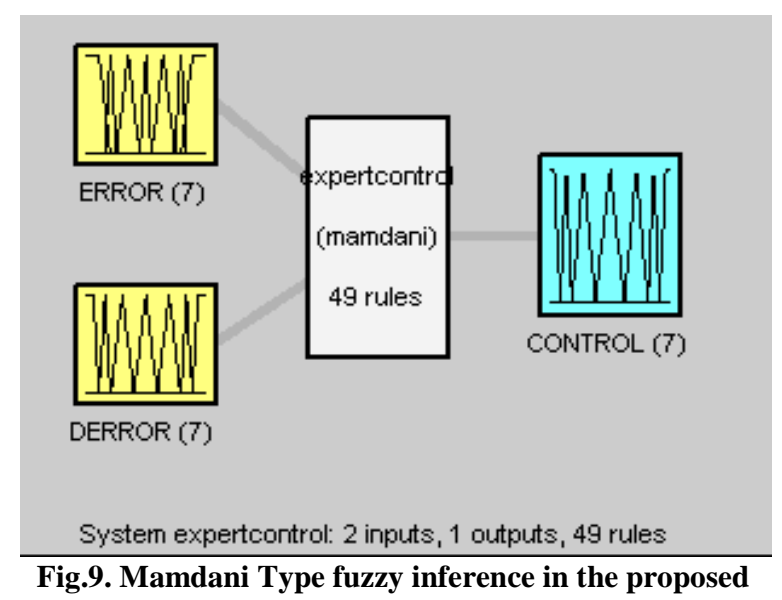
fuzzy logic controller

Surface viewer generates a 3-D control surface with two input variables and the output from fuzzy inference system as shown below in fig. 10 . 


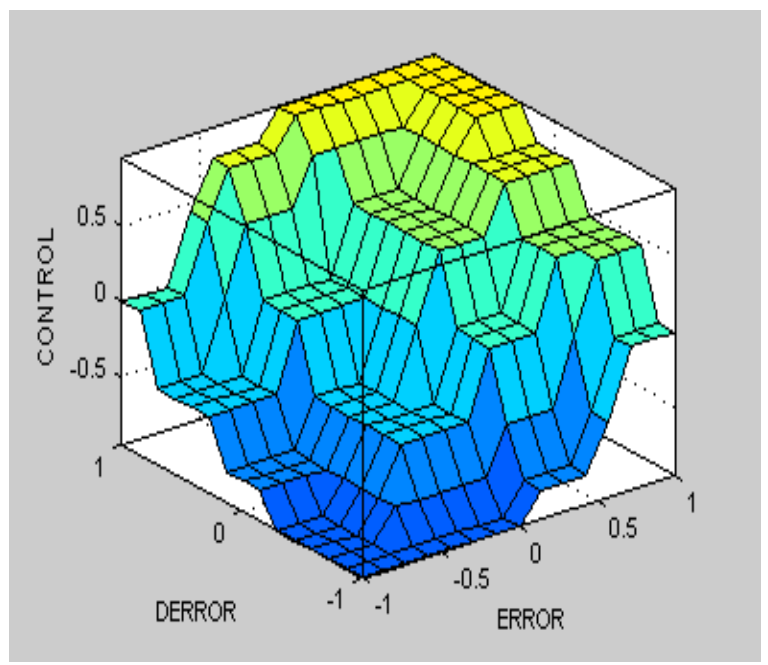

Fig.10. Control surface between inputs and output variable using fuzzy toolbox

The step response for fuzzy logic controller in higher order plant system is shown in Fig.11. There is no overshoot $\mathrm{M}_{\mathrm{p}}=0 \%$, rise time $\mathrm{t}_{\mathrm{r}}=1.55 \mathrm{sec}$ and settling time $t_{\mathrm{s}}=1.94 \mathrm{sec}$. The fuzzy logic controller with optimized membership function has better settling time and overshoot.

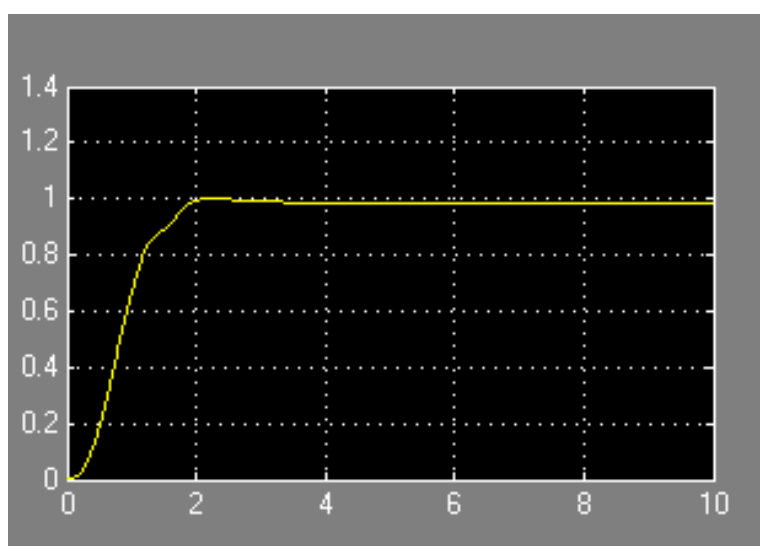

Fig.11. Step response for Fuzzy logic controller (FLC)

The summary of time response parameters like overshoot $\left(\mathrm{M}_{\mathrm{p}}\right)$,settling time $\left(\mathrm{t}_{\mathrm{s}}\right)$ and rise time $\left(\mathrm{t}_{\mathrm{r}}\right)$ through various techniques Ziegler -Nichols tuned PID controller, Fine-tuned PID controller and Fuzzy logic controller for the higher order plant system is given in Table.3.

Table.3.Time response parameters performance comparison of different controller

\begin{tabular}{|c|l|l|l|}
\hline $\begin{array}{c}\text { Controller/ } \\
\text { Parameters }\end{array}$ & ZNPIDC & FTPIDC & FLC \\
\hline $\begin{array}{c}\text { Overshoot } \\
\mathbf{M}_{\mathbf{p}}(\%)\end{array}$ & 60.7 & 35.5 & 0 \\
\hline $\begin{array}{c}\text { Rise time } \\
\mathbf{t}_{\mathbf{r}}(\mathbf{s e c})\end{array}$ & 0.43 & 0.165 & 1.55 \\
\hline $\begin{array}{c}\text { Settling time } \\
\mathbf{t}_{\mathbf{s}}(\mathbf{s e c})\end{array}$ & 7.43 & 2.03 & 1.94 \\
\hline
\end{tabular}

\section{CONCLUSION}

Simulation results using MATLAB/SIMULINK are discussed for Ziegler-Nichlos tuned PID controller, Fine-Tuned PID controller and fuzzy logic controller. Ziegler-Nichlos technique gives higher overshoot $M_{p}$, rise time $t_{r}$ and settling time $\mathrm{t}_{\mathrm{s}}$. Initial controller parameters obtained using $\mathrm{Z}-\mathrm{N}$ tuning formula needs to be adjusted again and again through simulation to get acceptable performances. Fine-Tuned PID controller gives smaller overshoot $\mathrm{M}_{\mathrm{p}}(\%)$, rise time $\mathrm{t}_{\mathrm{r}}$ and settling time $t_{s}$ as compared to Ziegler-Nichlos tuning technique. Fuzzy logic controller gives no overshoot $\mathrm{M}_{\mathrm{p}}(\%)$ and much smaller settling time $t_{\mathrm{s}}$ as compared to the Z-N tuning or Fine-Tuned PID controller. Hence, we can say that fuzzy logic controller with simple design approach gives much better performance than Ziegler-Nichlos tuned and Fined-Tuned PID controllers.

\section{REFERENCES}

[1] Zadeh, L. A., "Fuzzy Sets," Information and Control, Vol. 8, pp. 335-353, 1965

[2] J.-S. Roger Jang, (1997): "Fuzzy Logic Toolbox User's Guide COPYRIGHT 1984 - 1997 by The MathWorks", Inc. All Rights Reserved Cheng- Yuan Liou and YenTing Kuo.

[3] Ozdemir, E.; Ural, A.; Abut, N.; Karakas, E.; Olcer, E.; Karagoz, "Design of Fuzzy Logic Controller for DC-DC Converter Fedtraction Motor Drives Intelligent Control", IEEE International Symposium 1997.

[4] Visioli,.A., "Tuning of PID Controllers with Fuzzy Logic," IEEE Proceedings Control Theory and Applications, vol. 148, No. I , pp. 1-8, 2001.

[5] Desborough, L. D., Miller, R. M., 2002, Increasing customer value of industrial control performance monitoring-Honeywell's experience. Chemical Process Control-VI (Tuscon, Arizona, Jan. 2001, Vol. 98, AICHE Symposium Series No. 326, USA.

[6] Anavatti, S.G.; Salman, S.A.; Choi, J.Y., "Fuzzy and PID Controller forRobot Manipulator," IEEE Int Conf on Intelligent Agents, Web Tech and Internet Commerce, International Conf, Vol., No., pp.75-75, 2006.

[7] S.R. Vaishnav, Z. J. Khan, "Design and Performance of PID and Fuzzy Logic Controllers with Smaller Rule Set for Higher Order System", Proceeding of the World Congress on Engineering and Computer Science 2007, October 24-26, 2007, San Francisco, USA.

[8] Sheroz Khan, Salami Femi Abdulazeez, Lawal Wahab Adetunji, "Design and Implementation of an Optimal Fuzzy Logic Controller Using Genetic Algorithm, Journal of Computer Science Journal of Computer Science Vol.4, 2008.

[9] Shamsuzzoha, M.Skogestad, “ The set point Overshoot method: A simple and fast closed-loop approach for PID tuning”, Journal of Process Control, Vol.20, 2010.

[10] Essam Natsheh, Khalid A. Buragga," Comparison Between Conventional and Fuzzy Logic PID Controlling DC Motor", IJCSI, Vol7. Issue 5, September 2010.

[11]Farhad Aslam, Gagandeep Kaur, "Comparative Analysis of Conventional, P, PI, PID and Fuzzy Logic Controllers for the Efficient Control of Concentration in CSTR", 
International Journal of Computer Applications Volume 17, No.6, March 2011.

[12] Morteza Esfandyari , Mohammad Ali Fanaei, Hadi Zohreie "Adaptive Fuzzy Tuning of PID Controllers" Neural Compute \& Applic, Springer-Verlag London 2012.

[13] Rajkumar Bansal, A.Patra, Vijay Bhuria, Design of PID Controller for Plant Control and Comparison with Z-N PID Controller", International Journal of Emerging Technology and Advanced Engineering, Volume 2, Issue 4, April 2012.

[14] Shoubin Wang, Na Li, Fan Yang, "Resistance Furnace Temperature System on Fuzzy PID Controller", Journal of Information \& Computational Science 9: 92012.

[15] Jay Kumar, Richa Kapoor,Brijebdra, Hemant, Jyoti, "Comparative Analysis of Room Temperature Controller Using Fuzzy Logic and PID”, Advance in Electronic and Electric Engineering, Volume 3, Number 7 2013, pp. 853-858.

[16] Ahmed I. Mohamed, "Simplified Fuzzy Logic Controller Design for Higher Order Processes", International
Journal of Science and Research (IJSR), Volume 2 Issue 6, June 2013.

[17]Anil Kumar.K, Jyoshna .P, Seshadri .G, "Realization of Fuzzy Logic in Temperature Control System over PID”, International Journal of Engineering Research and Technology (IJERT), Vol. 3 Issue 7, July - 2014.

[18] Ritu Shakya, Kritika Rajonwal, Sanskriti Patel, Simta Dinkar, "Design and Simulation of PD,PID and Fuzzy logic Controller for Industry Application", International Journal of Information and Computation Technology, Volume 4, No. 4, 2014, pp 363-368.

[19] Mohamed Temam Nasri and Witold Kinsner, "A Comparison Between Fuzzy Fractional and Integer-Order Contrsoller For Small Satellites Attitude Control", IEEE 2014 Ryerson University Ontario, Toronto.

[20] H.Kala, D.Deepakraj, P.Gopalakrishnan, P.Vengadesan, M. Karumbal Iyyar, "Performance Evaluation of Fuzzy Logic and PID Controller for Liquid Level Process", JIREEICE Vol. 2, Issue 3, March 2014.

[21] Danilo Pelusi and Raffaele Mascella, "Optimal Control Algorithms for Second Order System", Journal of Computer Science, Vol.9, No.2, December 2014. 